\title{
The "FAMACHA" Chart - An Alternate to Manage Haemonchosis in Small Ruminants - A Review Article
}

\author{
V. Prashanth ${ }^{1}$, H. J. Kiran², Ram Kumar Rupner ${ }^{1}$, \\ Shivanagouda Patil ${ }^{3}$ and V.S. Prakash ${ }^{2}$ \\ ${ }^{1}$ ICAR-Indian Veterinary Research Institute, Izatnagar, Uttar Pradesh, India \\ ${ }^{2}$ Veterinary College, Shivamogga - Karnataka, India \\ ${ }^{3}$ College of Veterinary and Animal Sciences, Hisar - Haryana, India \\ *Corresponding author
}

Keywords

Haemaonchus contortus, Anaemia, FAMACHA,

Anthelmintic resistance

\section{Article Info}

Accepted:

15 March 2020

Available Online:

10 April 2020

\begin{abstract}
A B S T R A C T
Development of anthelmintic resistance has made it essential to develop alternative ways of worm control in animals. One of the most promising approaches is to treat only those animals which require attention in terms of worm management. "FAMACHA" method has facilitated quick identification of Haemaonchus contortus infected sheep and goats without the aid of any laboratory procedures and delivers the treatment only to those who require it. The visible signs of anaemia have been exploited as a simple and rapid diagnostic indicator through the development of the "FAMACHA" system, which involves the assessment of the colour of the conjunctival mucous membranes. The "FAMACHA" system was specifically developed to identify the animals on an individual basis which require treatment, to reduce anthelmintic resistance imposed by the usual and frequent treatment of all animals in the group. The "FAMACHA" chart assigns a number from 1 to 5 to each level of colour in the eyelid. The range of colours used in the "FAMACHA" system goes from Red to reddish pink, to pink, to pinkish-white, to white. The numbers 1 to 5 are assigned to each of these values. The "FAMACHA" system can be a valuable tool in helping to delay resistance issues in sheep and goat herds.
\end{abstract}

\section{Introduction}

In the era of anthelmintic resistance, it is the need of the hour to look for alternative ways of worm management. One of the most promising approaches is to treat only the animals which really require attention in terms of worm management. "FAMACHA" method has facilitated quick identification of Haemaonchus contortus infected sheep and goats without the aid of any laboratory procedures and delivers the treatment only to those who require it (Vatta et al., 2009; Kaplan et al., 2004) and also another 
economic strategy for control of $H$. contortus. This selective deworming strategy minimizes the use of drugs and thereby slowing down the development of drug-resistant. It may also aid in selective breeding decisions by identifying the animals that are most susceptible to $H$. contortus infection.

The name "FAMACHA" was coined to describe the system evolved for treating only those animals unable to cope with current Haemonchus contortus challenge on pasture, by using clinical anaemia as the determinant. It is an acronym (FAffa MAlan CHArt) derived from the name of the originator of the idea a South African scientist, Dr. Faffa Malan (Van et al., 1997; Bath et al., 1996). The visible signs of anaemia have been exploited as a simple and rapid diagnostic indicator through the development of the "FAMACHA" system, which involves the assessment of the colour of the conjunctival mucous membranes (Van Wyk and Bath, 2002). For this, first animals are restrained, and the lower eyelids are examined and scored against a standardized set of five colours ranging from red-pink (normal) to white (terminal anaemia) (Malan et al., 2001). The goal of the "FAMACHA" system is to decrease and delay resistance by selective deworming the animals in the herd that are showing symptoms of parasite infection.

The "FAMACHA" system was specifically developed to identify the animals on an individual basis which require treatment, to reduce anthelmintic resistance imposed by the usual and frequent treatment of all animals in the group. However, the classifications can also be used as the basis for whole-flock or herd anthelmintic treatments, when a proportion of animals fall below a threshold value. This approach requires frequent assessments to ensure the early detection and treatment of animals with subclinical haemonchosis, with a recommended schedule of inspections at 7 to 10-day intervals, once anaemia is detected in a small monitor group (Van Wyk and Bath, 2002). In addition to a dramatic reduction in the proportion of anthelmintic treatments given, 'repeat offender' animals can be identified and culled, as there is a high heritability of "FAMACHA" score for both sheep (Riley and Van Wyk, 2009) and goats (Mahieu et al., 2007).

The "FAMACHA" chart (Fig. 1) assigns a number from 1 to 5 to each level of colour in the eyelid. A normal eyelid of a healthy sheep or goat is dark red, indicating that no anaemia is present and the animal is presumed to be free of dangerous levels of parasites. The range of colours used in the "FAMACHA" system goes from Red to reddish pink, to pink, to pinkish-white, to white. The numbers 1 to 5 are assigned to each of these values, respectively. Although some dispute remains as to where the cut off for treatment should be, producers generally treat animals with a score of a 4 or a 5 , and in some cases a 3 . Since goats are affected more seriously by internal parasites than sheep, the cut-offs for treatment in goats may be lower than in sheep to prevent serious loss from occurring. Treatment also depends on the class of animal and the relative susceptibility of that class of animal (i.e. buck, doe, kid, lamb). Sheep and goat farmers can be trained and certified to use the "FAMACHA" system. The "FAMACHA" system can be a valuable tool in helping to delay resistance issues in sheep and goat herds.

\section{General guidelines for using the FAMACHA card}

Always check eyes outside in direct, natural light.

Always use the card when scoring your animals and do not try to score from a memory of the colours. 
Use the same chart for all the animals in flock.

How to examine your animals with the FAMACHA card

Proper FAMACHA scoring technique includes exposing the lower eye mucous membranes and matching them to the equivalent colour on the FAMACHA card (Fig. 2). COVER, PUSH, PULL, POP is a 4step process describing the proper technique.

COVER the eye by rolling the upper eyelid down over the eyeball

PUSH down on the eyeball. An easy way to tell if you are using enough pressure is that you should see that the eyelashes of the upper eyelid are curling up over your thumb

PULL down the lower eyelid.

POP! The mucous membranes will pop into view. Make sure that you do not score the inner surface of the lower eyelid, but rather score the bed of mucous membranes.

Interpretation of the results using FAMACHA chart

Animals in FAMACHA category $4 \& 5$ : Always deworm sheep \& goats in these categories.

Animals in FAMACHA category $1 \& 2$ : Don't deworm animals in these categories unless there is other evidence of parasitic diseases such as the presence of diarrhoea, poor body condition, dull hair coat or abnormal fleece.

Animals in FAMACHA category 3: Consider deworming if:

$>10 \%$ of flock/herd scores a 4 or 5 .
Lambs and kids (usually recommended).

Animals in poor body condition.

Concerned about an animal's general health and well being, for example, if an animal is in poor body condition, or suffering from another disease.

Precautions to be taken while using FAMACHA chart

FAMACHA is only applicable where the $H$. contortus is the main GIN parasite causing clinical disease.

Redness of the ocular membranes can be caused by eye disease, environmental irritants, and systemic disease. Though they are uncommon, these conditions can mask anaemia.

Other causes of anaemia exist, but they are uncommon compared to barber pole worm infection during the grazing season.

An elevated FAMACHA score is not the only reason to deworm an animal. GIN can play a role in other signs of disease including:

Diarrhoea

Bottle jaw

Poor body condition

Dull hair coat or abnormal fleece

Exercise or heat intolerance

General recommendations for effective management of $H$. contortus

Effective management of $H$. contortus cannot be accomplished by using only one management factor; it is a combination of factors that will produce the most effective defence against $H$. contortus.

Anthelmintics should be used only to treat animals when necessary.

Use of different classes of anthelmintics on rotation basis will help in slowing down 
the development of resistance.

The FAMACHA system can be used to identify the animals which are in need of anthelmintic treatment.
Pasture management is a key component in managing $H$. contortus in sheep and goat rearing.

Figure.1 FAMACHA chart that depicts the eyelid colour associated with a level of anaemia and FAMACHA score

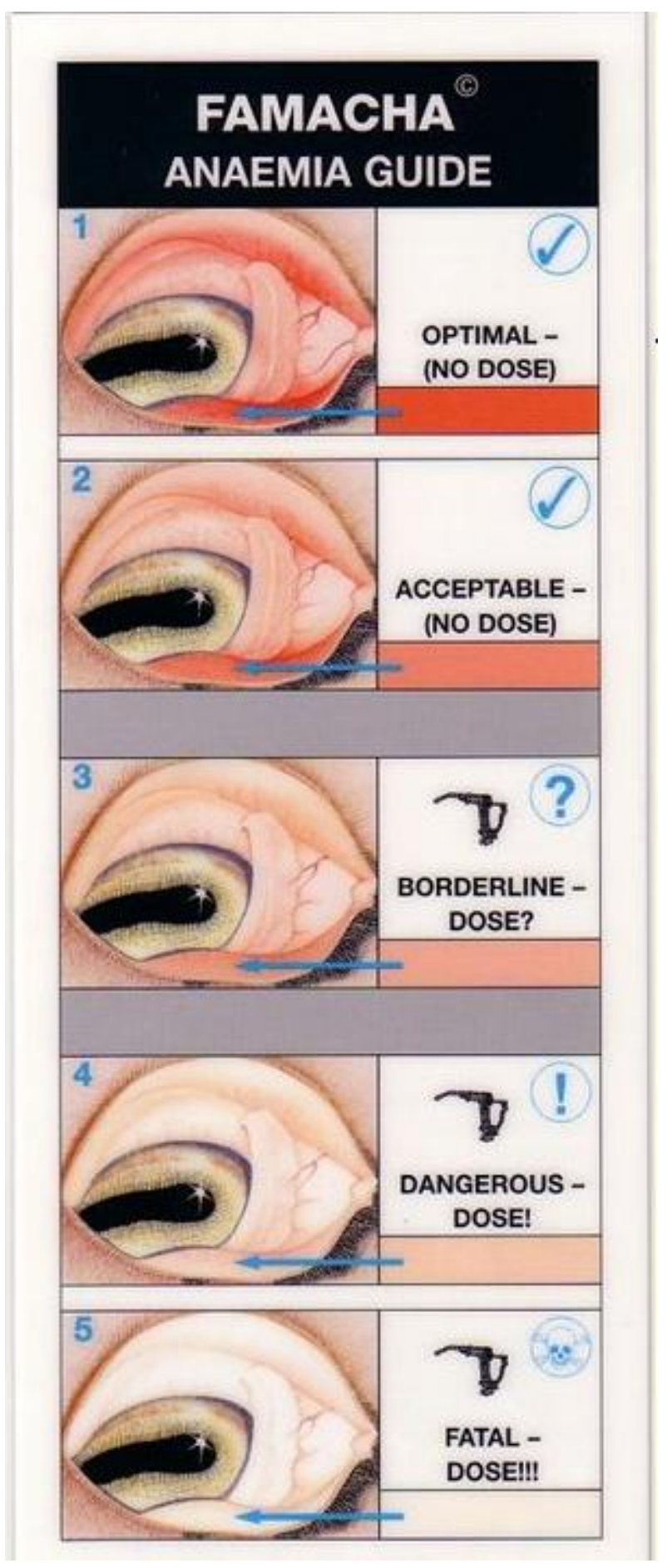

\section{FAMACHA® method}

Eye colour chart with five colour categories

Compare chart with colour of conjunctival mucous membranes of sheep or goat

Classification into one of five colour categories:

1-Not anaemic

5-Severly anaemic 
Figure.2 FAMACHA scoring COVER, PUSH, PULL and POP method

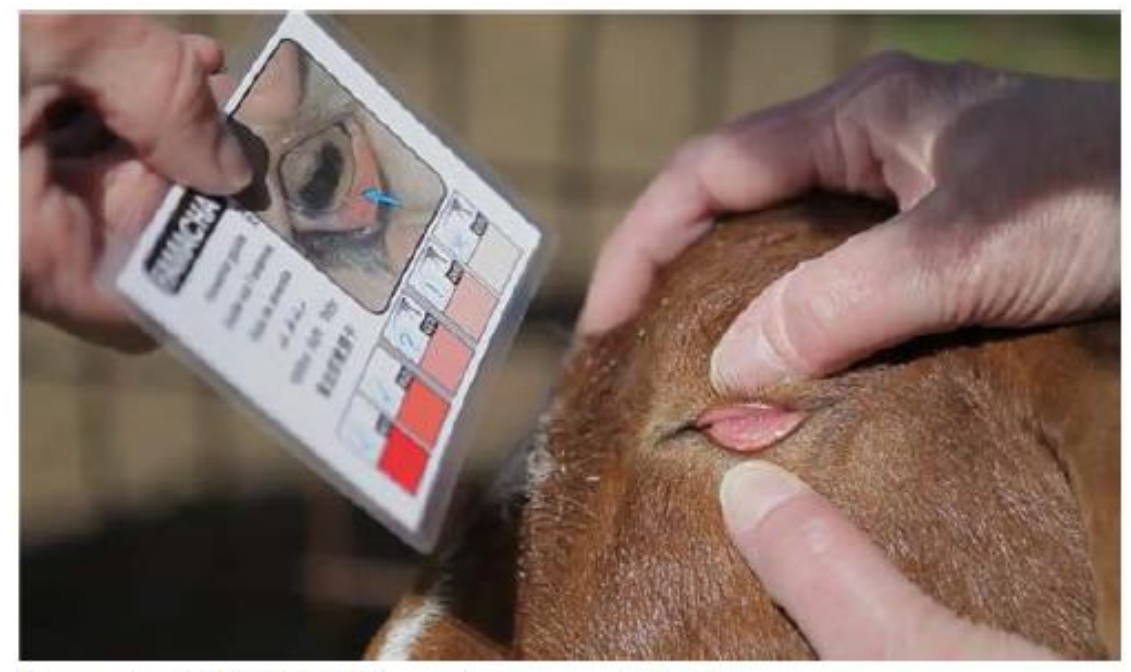

\section{References}

Bath G.F., Malan F.S., Van Wyk J.A., The "FAMACHA" Ovine Anaemia Guide to assist with the control of haemonchosis, in: Proceedings of the 7th Annual Congress of the Livestock Health and Production Group of the South African Veterinary Association, Port Elizabeth, 5-7 June 1996, p. 5.

Kaplan RM, Burke JM, Terrill TH, Miller JE, Getz WR, Mobini S, Valencia E, Williams MJ, Williamson LH, Larsen M and Vatta AF. 2004. Validation of the FAMACHA eye colour chart for detecting clinical anemia in sheep and goats on farms in the southern United States. Veterinary Parasitology. 123: 105-120

Malan, F.S., Van Wyk, J.A., Wessels, C.D., 2001. Clinical evaluation of anaemia in sheep: early trials. Onderstepoort J. Veterinary Research. 68, 165e174.

Mahieu, M., Arquet, R., Kandassamy, T., Mandonnet, N., Hoste, H., 2007. Evaluation of targeted drenching using "FAMACHA" method in Creole goat: reduction of anthelmintic use, and effects on kid production and pasture contamination. Veterinary Parasitology.
$146,135 \mathrm{e} 147$.

Riley, D.G., Van Wyk, J.A., 2009. Genetic parameters for FAMACHA score and related traits for host resistance/resilience and production at differing severities of worm challenge in a Merino flock in South Africa. Veterinary Parasitology. 164, 44e52.

Van Wyk J.A., Malan F.S., Bath G.F., 1997. Rampant anthelmintic resistance in sheep in South Africa - what are the options? in: Managing Anthelmintic Resistance in Endoparasites. Workshop held at the 16th International Conference of the World Association for the Advancement of Veterinary Parasitology, 10-15 August 1997, Sun City, South Africa, pp. 51-63.

Van Wyk, J.A., Bath, G.F., 2002. The FAMACHA system for managing haemonchosis in sheep and goats by clinically identifying individual animals for treatment. Veterinary Research. 33, $509 \mathrm{e} 529$.

Vatta AF, Waller PJ, Githiori JB and Medley GF. 2009. The potential to control Haemonchus contortus in indigenous South African goats with copper oxide wire particles. Veterinary Parasitology. 162: 306-313. 


\section{How to cite this article:}

Prashanth, V., H. J. Kiran, Ram Kumar Rupner, Shivanagouda Patil and Prakash, V. S. 2020. The "FAMACHA" Chart - An Alternate to Manage Haemonchosis in Small Ruminants - A Review Article. Int.J.Curr.Microbiol.App.Sci. 9(04): 1908-1913.

doi: https://doi.org/10.20546/ijcmas.2020.904.226 